\title{
High resolution modelling of the extreme precipitation event over Algiers in November 2001
}

\author{
S. A. Moore, C. Wilson, and S. Bell \\ Met Office, FitzRoy Road, Exeter, EX1 3PB, UK \\ Received: 24 October 2004 - Revised: 24 February 2005 - Accepted: 4 March 2005 - Published: 11 May 2005
}

\begin{abstract}
Between 18:00 UTC on Friday 9th November and 12:00 UTC on Saturday 10th November $2001260 \mathrm{~mm}$ of rainfall was recorded at Bouzareah, compared to the November average of just $96 \mathrm{~mm}$. This extreme rainfall resulted in landslides and flooding, causing immense damage to the Bab-el-Oued district of Algiers and affected the lives of more than 2000 people. In this paper, key results from a modelling study of this event using the UK Met Office Unified Model at global $(60 \mathrm{~km})$, regional $(20 \mathrm{~km})$ and national $(4 \mathrm{~km})$ horizontal resolutions are described. In general, it is found that the event could be well forecast with increases in resolution leading to better predictions of both the distribution and intensity of the rainfall. The role of the local orography and latent heating are also discussed.
\end{abstract}

\section{Introduction}

Strong cyclogenesis events are not uncommon in the Mediterranean region but events of such severity as the one experienced in Algiers are. The extreme precipitation encountered in Algiers was partly the result of a strong cyclogenesis event that began with a low pressure system originating over Scandinavia moving south over Europe to the Mediterranean basin. Coupled with an influx of cold air over the course of the 9th November from the west, this led to a decrease in atmospheric pressure of $1006 \mathrm{hPa}$ to $997 \mathrm{hPa}$ in the twenty four hours from 12:00 UTC on the 9th to 12:00 UTC on the 10th November. At the same time, an increase in the amount of warm, moist air being lifted up into the atmosphere over the Mediterranean Sea ultimately led to the extreme amount of precipitation.

A multiple resolution modelling study of this event is conducted to investigate not only the predictability of the event, but also identify any potential factors that may have amplified the total precipitation amounts. Numerical experiments at a resolution of $4 \mathrm{~km}$ looking into the role of the local orography and latent heating are therefore conducted.

Correspondence to: S. A. Moore

(stuart.moore@metoffice.gov.uk)

\section{Numerical Modelling}

All model runs conducted in this study are performed using the UK Met Office Unified Model (UM). The underlying formulation of the model is a non-hydrostatic, semi-implicit semi-Lagrangian dynamical core called the "New Dynamics" and is described in Cullen et al. (1997) and Davies et al. (1999). The model physics includes a CAPE closure based convection scheme, a mixed phase large scale precipitation scheme and a Richardson Number based boundary layer mixing scheme. An overview of these schemes, as well as a description of how orography is represented in the UM, is given by Webster et al. (2003).

The coarsest resolution model runs are performed using a $60 \mathrm{~km}$ global model with a full 6-hourly 3D-Var data assimilation cycle (Lorenc et al., 2000), using all available conventional and satellite observations. Two day $(\mathrm{T}+48)$ forecasts are produced at midnight and midday on each day. The same model runs generate lateral boundary conditions for the regional scale $20 \mathrm{~km}$ model. The $20 \mathrm{~km}$ mesoscale version of the UM, called the "North Atlantic European" model, is used for the regional scale part of the study. As shown in Fig. 1, the model domain covers Europe, much of the north Atlantic and north Africa. The initial conditions for this model are derived from interpolated $60 \mathrm{~km}$ model output. This model also uses a 6-hourly 3D-Var data assimilation cycle and is configured to provide $\mathrm{T}+36$ hour forecasts beginning at 00:00 UTC, 06:00 UTC, 12:00 UTC and 18:00 UTC on each day up to and during the event, starting on the 7th November. This model also produces the lateral boundary conditions for the high resolution $4 \mathrm{~km}$ model.

The $4 \mathrm{~km}$ limited area model is centred on and covers an area of $577600 \mathrm{~km}^{2}$ around Algiers using a $190 \times 190$ grid. It is run, without data assimilation, out to $\mathrm{T}+36$ from 09:00 UTC on the 9th November ${ }^{1}$. The initial conditions for the $4 \mathrm{~km}$ model are derived by interpolating output from the $20 \mathrm{~km}$ model.

\footnotetext{
${ }^{1}$ The $\mathrm{T}+36$ hour forecast length and 09:00 UTC start time was chosen for technical reasons.
} 


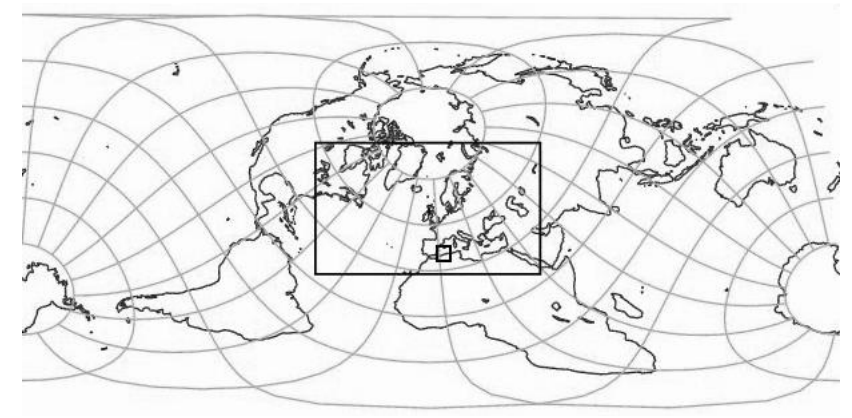

Fig. 1. Schematic showing the $20 \mathrm{~km}$ model domain nested within the $60 \mathrm{~km}$ global model and the $4 \mathrm{~km}$ model domain nested within the $20 \mathrm{~km}$ domain and centred on Algiers.

\section{Results}

The nature of the event being studied means that the precipitation fields are the most important in terms of analysing the models ability to forecast an event as extreme as the one that hit Algiers. The following sections show how the forecasts of total precipitation amount, which comprises of the dynamic and convective rainfall and snowfall, vary as the model resolution, domain orography and latent heating characteristics are varied.

\subsection{Effect of change in horizontal resolution}

Figure 2 shows 24-hour pointwise accumulations of the total model precipitation for the period 12:00 UTC on Friday 9th to 12:00 UTC on Saturday 10th November. The $60 \mathrm{~km}$ and $20 \mathrm{~km}$ forecasts were started at $00 \mathrm{Z}$ on the 9 th while the $4 \mathrm{~km}$ forecast was started nine hours later at 09:00 UTC on the 9th.

Both the $20 \mathrm{~km}$ and $4 \mathrm{~km}$ models have maximum accumulations greater than the $119 \mathrm{~mm}$ forecast by the $60 \mathrm{~km}$ model. However, these totals, $167 \mathrm{~mm}$ and $166 \mathrm{~mm}$ in the $20 \mathrm{~km}$ and $4 \mathrm{~km}$ models respectively, are much less than the observed maximum for the event of $260 \mathrm{~mm}$ recorded at Bouzareah during the period 18:00 UTC on the 9th to 12:00 UTC on the 10th November. Rainfall totals for Bouzareah and other selected rain gauge sites in the surrounding area are shown in Fig. 3. Despite this, the model accumulations still exceed the monthly average for November of just $96 \mathrm{~mm}$ and would have alerted forecasters to the occurrence of a major precipitation event. While each model has the rainfall positioned correctly along the Algerian coastline, only the $20 \mathrm{~km}$ and $4 \mathrm{~km}$ models give some idea as to the localised nature of the most intense precipitation. However, it is noted that the position of the maximum rainfall in all of the models is to the east of Algiers, away from the location of the recorded maximum at Bouzareah to the west of Algiers. The area of maximum precipitation in the $20 \mathrm{~km}$ and $4 \mathrm{~km}$ models in particular is concentrated to the east of Algiers with less rainfall over Algiers itself. It is believed this is most likely due to the sensitivity of the model forecasts to the initial conditions. Indeed, forecasts from the $4 \mathrm{~km}$ model starting at 09:00 UTC on the 8th November and 03:00 UTC and 15:00 UTC on the 9th November (not shown) do exhibit some sensitivity of the intensity and location of the precipitation field to the forecast start time.

A number of numerical experiments were carried out using the $4 \mathrm{~km}$ model which looked at the role of orography and latent heating in the precipitation event. The following sections summarize the main results from these experiments.

\subsection{Effect of orography}

Two experiments were conducted which altered the orography of the $4 \mathrm{~km}$ model domain. The first imposed a maximum orographic height of $750 \mathrm{~m}$ and the second a maximum height of $400 \mathrm{~m}$. The maximum height in the full orographic field is just over $1.6 \mathrm{~km}$. Figure 4 compares the full, unaltered orography (Fig. 4a) against the two scenarios where the maximum height is $750 \mathrm{~m}$ (Fig. 4b) and $400 \mathrm{~m}$ (Fig. 4c).

For the 24-hour period between 12:00 UTC on the 9th to 12:00 UTC on the 10th November, Fig. 5 compares the total precipitation accumulation from the model run with unaltered orography with the accumulations from the two runs where the domain orography is altered.

Although there is little obvious difference to the distribution of the precipitation, greater, more localised precipitation is forecast when the maximum orographic height is reduced. This is evident in the coastal region to the east of Algiers where the precipitation totals for the 24-hour period increase from $166 \mathrm{~mm}$ using the unaltered orography to $177 \mathrm{~mm}$ where a maximum height of $750 \mathrm{~m}$ is imposed and $187 \mathrm{~mm}$ when the maximum height is $400 \mathrm{~m}$. There is a second region of increased precipitation when the maximum orographic height is reduced further inland and to the southwest of Algiers. Here, an increase in total precipitation of up to $30 \mathrm{~mm}$ on the control run is found and appears related to the removal of a $1300 \mathrm{~m}$ peak that is present in the full orography field (Fig. 4a).

With the majority of the peaks removed from the local topography, the increase in precipitation is less likely due to orographic enhancement but rather the large scale flow adjusting to the revised orography. In effect, the role of the local orography as a blocking feature has been reduced. Indeed, compared to the control run, the relative humidity at lower levels (not shown) reveals larger regions of moist air moving inland as the maximum orographic height is reduced. This result also lends support to the suggestion of Tripoli et al. (2002) that the precipitation event itself was not overly enhanced by the local orographic detail.

\subsection{Effect of latent heat}

The studies of Genovés and Jansà (2002) and Hamadache et al. (2002) discussed the role of the latent and sensible heat fluxes in the generation and subsequent development of the cyclone that was located over Algiers. To investigate this further, two runs of the $4 \mathrm{~km}$ model were made with the values of the latent heat of condensation at $0^{\circ} \mathrm{C}\left(L_{c}\right)$ and latent 


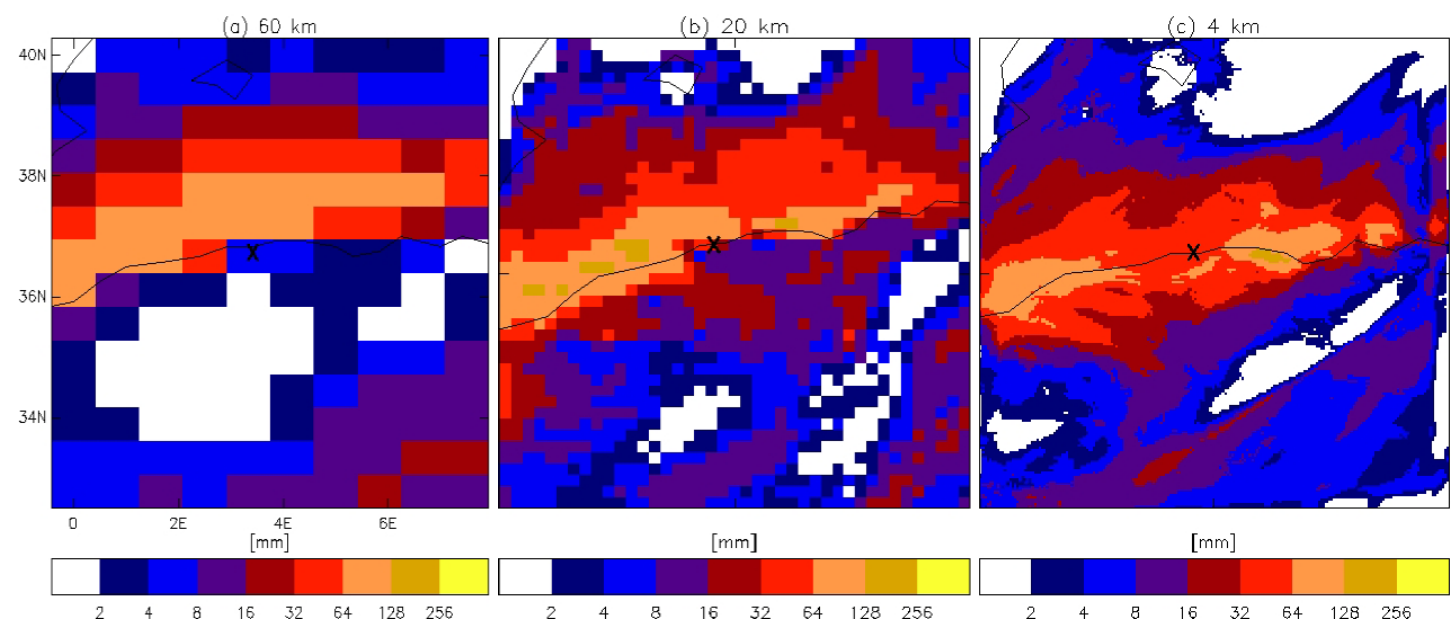

Fig. 2. 24-hour accumulations of the total precipitation amount for the period 12:00 UTC on the 9th November to 12:00 UTC on the 10th November for (a) the $60 \mathrm{~km}$ model, (b) the $20 \mathrm{~km}$ model and (c) the $4 \mathrm{~km}$ high resolution model. In each plot, the "X" marks the position of Algiers.

heat of fusion at $0^{\circ} \mathrm{C}\left(L_{f}\right)$ reduced first by half and second by a factor of four. The first run used $L_{c}=1.251 \times 10^{6} \mathrm{Jkg}^{-1}$ and $L_{f}=0.167 \times 10^{6} \mathrm{Jkg}^{-1}$, while the second run reduced these values further to $L_{c}=0.626 \times 10^{6} \mathrm{Jkg}^{-1}$ and $L_{f}=0.084 \times 10^{6} \mathrm{Jkg}^{-1}$. The control run used $L_{c}=2.502 \times 10^{6} \mathrm{Jkg}^{-1}$ and $L_{f}=0.334 \times 10^{6} \mathrm{Jkg}^{-1}$. Figure 6 shows the differences in the total precipitation fields from the three runs for the 24-hour period 12:00 UTC on the 9th to $12: 00$ UTC on the 10th November.

Compared to the change in precipitation fields that resulted from changes to the domain orography, reducing the effect of latent heating has had a much larger effect on the total precipitation amounts, altering both the precipitation amount and its distribution. In general, reducing the role of latent heating has led to a decrease in precipitation, particularly in the regions of most intense rainfall along the coast to the east of Algiers.

Compared to the control run maximum accumulation of $166 \mathrm{~mm}$, halving the contribution of latent heating (Fig. 6b) has resulted in a maximum accumulation of just $130 \mathrm{~mm}$. This is less than the maximum accumulation for the same period forecast by the $20 \mathrm{~km}$ model. There are, however, a number of small areas, particularly to the south and south west of Algiers, where the precipitation amount has increased compared to the control run.

When $L_{c}$ and $L_{f}$ are reduced by a factor of four (Fig. 6c), the differences that were seen when $L_{c}$ and $L_{f}$ were halved simply become more exaggerated and the maximum precipitation accumulation is now only $125 \mathrm{~mm}$. The region to the east of Algiers in particular is now indicating differences of up to $75 \mathrm{~mm}$ less precipitation than is found in the control run for the same 24-hour period. While, like in Fig. 6b, local increases in precipitation, compared to the control run, are found to the south and south west of Algiers, there is also a large region of less intense precipitation along the coast to the

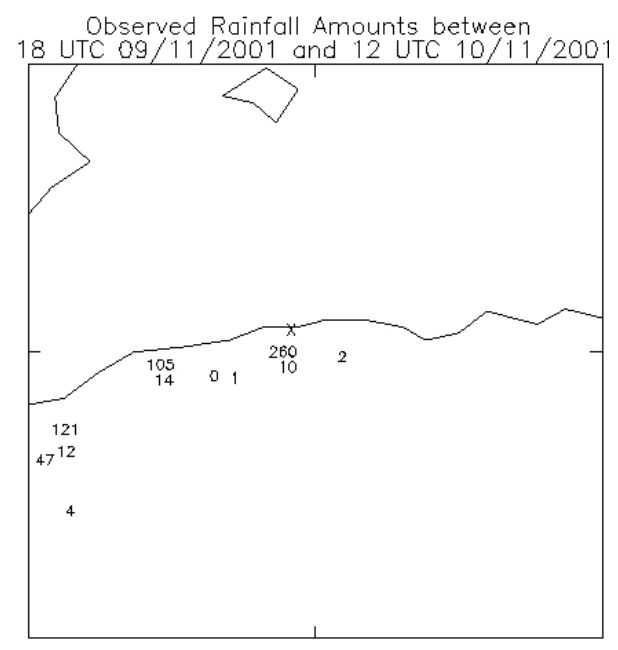

Fig. 3. Rainfall map showing 18-hour accumulations of rainfall (in $\mathrm{mm}$ ) as recorded by various rain gauge sites located around Algiers. Bouzareah recored $260 \mathrm{~mm}$ while Cap-Tenes recorded $105 \mathrm{~mm}$. The "X" marks the position of Algiers.

west of Algiers. Here, reducing the effect of latent heating has led to a $40 \mathrm{~mm}$ reduction in the amount of precipitation forecast by the model compared to the control run.

\section{Conclusions}

The numerical simulations presented in this paper have shown the extreme precipitation event of the 9th and 10th November 2001 to be well forecast at global $(60 \mathrm{~km})$, regional $(20 \mathrm{~km})$ and high resolution $(4 \mathrm{~km})$ scales. Whilst it is shown that high resolution limited area models clearly have an important role to play in being able to forecast and study such events, the use of data assimilation and supporting 


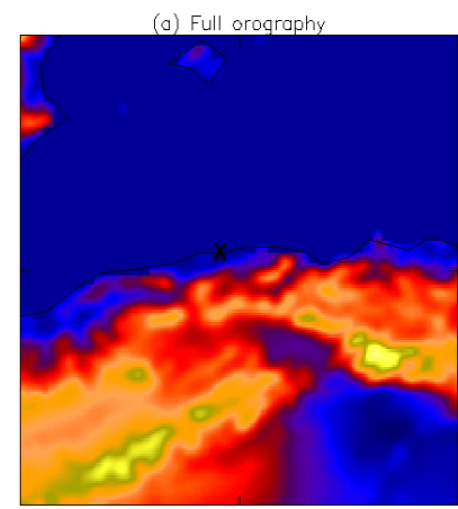

$[\mathrm{m}]$

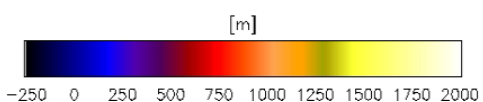

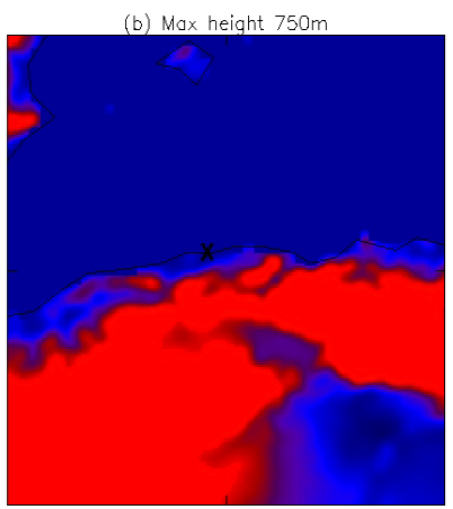

$[\mathrm{m}]$

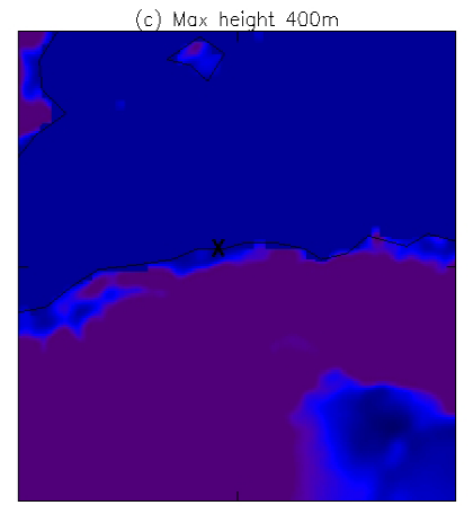

$[\mathrm{m}]$

Fig. 4. Plots showing, for the $4 \mathrm{~km}$ model domain, (a) the unaltered domain orography, (b) the orography when a maximum height of $750 \mathrm{~m}$ is imposed and (c) the orography when a maximum height of $400 \mathrm{~m}$ is imposed. In each plot, the " $\mathrm{X}$ " marks the position of Algiers.

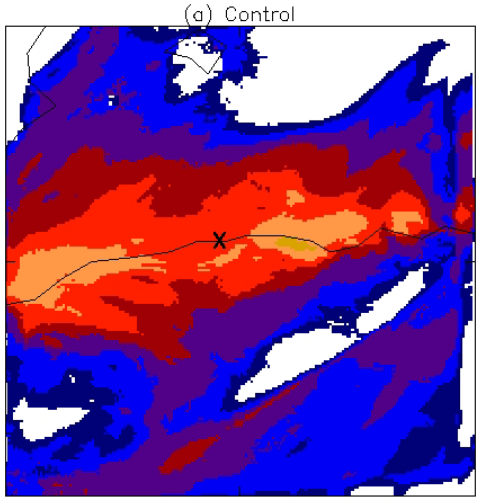

$[\mathrm{mm}]$

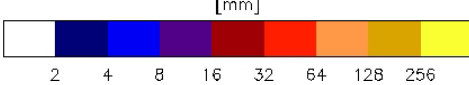

(b) Control - Max height $750 \mathrm{~m}$

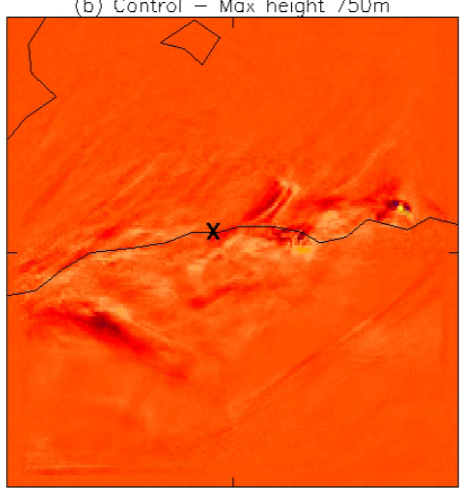

$[\mathrm{mm}]$

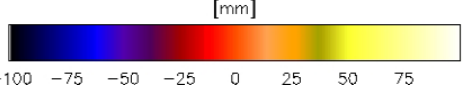

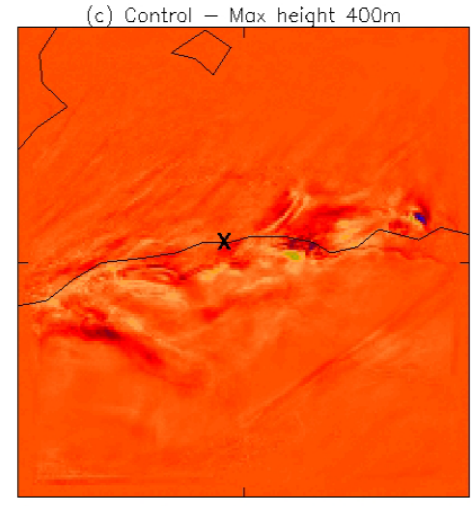

$[\mathrm{mm}]$

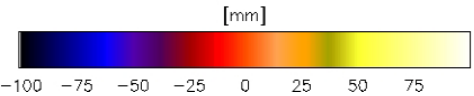

Fig. 5. Plots showing (a) the 24-hour accumulation of the total precipitation amount for the period 12:00 UTC on 9th November to 12:00 UTC on 10th November using the $4 \mathrm{~km}$ model with the original orography and for the same 24-hour period, (b) the difference in total precipitation amount between the control run and the run where the maximum orographic height is $750 \mathrm{~m}$ and (c) the difference in total precipitation amount between the control run and the run with a maximum orographic height of $400 \mathrm{~m}$. In each plot, the "X" marks the position of Algiers.

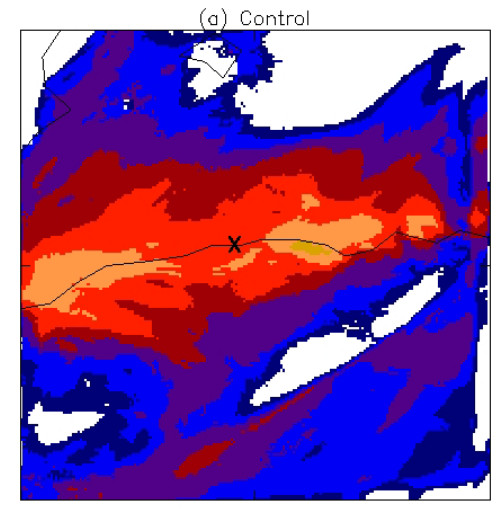

$[\mathrm{mm}]$

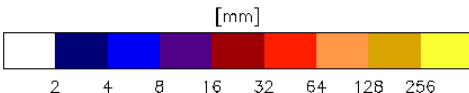

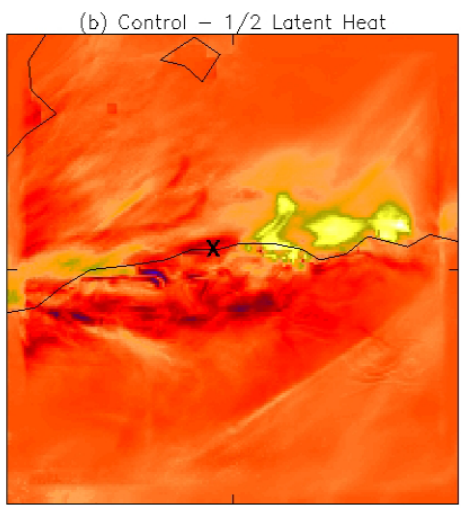

$[\mathrm{mm}]$

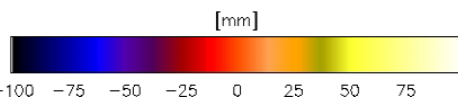

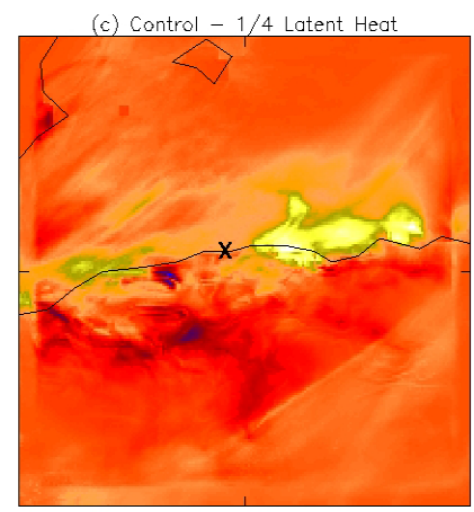

$[\mathrm{mm}]$

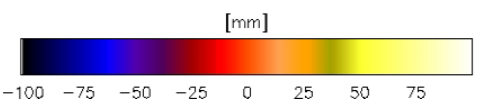

Fig. 6. Plots showing (a) the 24-hour accumulation of the total precipitation amount for the period 12:00 UTC on 9th November to 12:00 UTC on 10th November using the $4 \mathrm{~km}$ model where $L_{c}$ and $L_{f}$ have their original values and for the same 24-hour period, (b) the difference in total precipitation amount between the control run and the run where $L_{c}$ and $L_{f}$ are halved and (c) the difference in total precipitation amount between the control run and the run where $L_{c}$ and $L_{f}$ are reduced by a factor of four. In each plot, the "X" marks the position of Algiers. 
observations remain vital so that the location of the most intense precipitation may be better predicted.

In accordance with the results of earlier studies, experiments with the $4 \mathrm{~km}$ model suggest that latent heating played a major role in the development of this extreme precipitation event while the role of the local orography was to block low level moisture from reaching inland rather than enhance the precipitation.

Acknowledgements. The authors would like to thank B. Hamadache and K. Chikhar of the Office National de la Météorologie, Alger for their contribution to this work.

Edited by: L. Ferraris

Reviewed by: C. Adamo and another referee

\section{References}

Cullen, M. J. P., Davies, T., Mawson, M. H., James, J. A., Coulter, S. C., and Malcolm, A.: An overview of numerical methods for the next generation of NWP and climate models, in: Numerical methods in atmospheric and ocean modelling. The Andre Robert memorial volume, edited by: Lin, C., Laprise, R., and Ritchie, H., pp. 425-444, Canadian Meteorological and Oceanographic Society, Ottawa, Canada, 1997.
Davies, T., Cullen, M. J. P., Mawson, M. H., and Malcolm, A. J.: A New Dynamical Formulation for the UK Meteorological Office Unified Model, in Proceedings of ECMWF seminar on recent developments in numerical methods for atmospheric modelling, 711 September 1998, pp. 202-225, European Centre for MediumRange Weather Forecasts, Shinfield Park, Reading, Berkshire, RG2 9AX, UK, 1999.

Genovés, A. and Jansà, A.: Diabatic Processes Contribution to the November 2001 Storm, in: Mediterranean Storms: Proceedings of the 4th EGS Plinius Conference, published on CD-ROM (ISBN 84-7632-792-7), 2002.

Hamadache, B., Terchi, A., and Brachemi, O.: Study of the meteorological situation which affected the west and the center of Algeria in general and Bab-el-Oued in particular in the 10th November 2001, in: Mediterranean Storms: Proceedings of the 4th EGS Plinius Conference, published on CD-ROM (ISBN 847632-792-7), 2002.

Lorenc, A. C., Ballard, S. P., Bell, R. S., Ingleby, N. B., Andrews, P. L. F., Barker, D. M., Bray, J. R., Clayton, A. M., Dalby, T., Li, D., Payne, T. J., and Saunders, F. W.: The Met. Office Global 3-Dimensional Variational Data Assimilation Scheme, Q. J. R. Meteorol. Soc., 126, 2991-3012, 2000.

Tripoli, G. J., Pinori, S., Dietrich, S., Panegrossi, G., Mugnai, A., and Smith, E.: The 9-10 November, 2001 Algerian Flood: A Polar Low?, in: Mediterranean Storms: Proceedings of the 4th EGS Plinius Conference, published on CD-ROM (ISBN 84-7632-7927), 2002.

Webster, S., Brown, A. R., Cameron, D. R., and Jones, C. P.: Improvements to the representation of orography in the Met Office Unified Model, Q. J. R. Meteorol. Soc., 129, 1989-2010, 2003. 